\title{
$O$ desencontro entre desejo e realidade: a "indústria" da cesariana entre mulheres de camadas médias no Rio de Janeiro, Brasil
}

| ${ }^{1}$ Junia Espinha Cardoso, ${ }^{2}$ Regina Helena Simões Barbosa |

Resumo: O artigo apresenta resultados de uma pesquisa qualitativa que buscou apreender e compreender, através da percepção e experiência de mulheres de camadas médias, o desencontro entre o desejo pelo parto vaginal e o desfecho em cesariana. Quinze usuárias de planos privados de saúde foram entrevistadas sobre suas experiências e percepções relativas ao pré-natal e parto. Os resultados evidenciaram uma (sutil ou explícita) interferência do obstetra sobre a escolha das mulheres, influenciando o desfecho em cesariana e sugerindo que, para muitas mulheres, não está sendo possível escapar das "armadilhas" de um modelo biomédico mercantilizado, interventor e iatrogênico, institucionalizado e legitimado pela sociedade. A pesquisa pretende contribuir para ações que estimulem o exercício da cidadania feminina nos processos decisórios que envolvem as questôes da saúde reprodutiva, preservando e garantindo a experiência do parto como um direito inalienável das mulheres, seus companheiros e familiares.

Palavras-chave: parto cesáreo; camadas médias; gênero; direitos reprodutivos.
1 Secretaria Municipal de Saúde e Defesa Civil do Rio de Janeiro, Superintendência de Promoção da Saúde. Endereço eletrônico: juniasmsdcrj@gmail.com

${ }^{2}$ Instituto de Estudos em Saúde Coletiva da Universidade Federal do Rio de Janeiro. 


\section{Introdução}

Apesar dos avanços científicos e da moderna tecnologia utilizada na assistência ao ciclo gravídico-puerperal, ainda vivemos no Brasil uma realidade preocupante no que diz respeito à assistência ao parto.

A origem da obstetrícia ocidental foi marcada pela apropriação, pela medicina científica, do saber popular feminino consolidado no vasto conhecimento empírico das parteiras. Ao longo do processo histórico de crescente intervenção médica e social sobre o corpo feminino, o parto foi sendo gradativamente dominado por tecnologias e intervenções (VIEIRA, 2002; MELO, 1983).

A medicalização e a redefinição do parto, pela biomedicina, como um acontecimento problemático, justificam uma intervenção "técnica" que "garante um bom desfecho". Tal representação foi lentamente substituindo o conhecimento tradicional feminino neste campo. A parturição, assim, tornou-se uma situação clínica, um acontecimento patológico, com intervençōes tornadas "necessárias" (CHACHAN, 2006).

Em todo o mundo, o aumento das taxas de cesarianas vem tornando o cenário do nascimento preocupante. Essas taxas, que começaram a apresentar uma aceleração progressiva a partir da década de 1970, transformaram-se em uma verdadeira epidemia (DIAS, 2001; CURY, 2006), tornando-se cada vez mais um problema de Saúde Pública.

No Brasil, nos hospitais da rede do Sistema Único de Saúde (SUS), essas taxas estão atualmente em torno de $26 \%$. Embora tenha se reduzido consideravelmente nos últimos anos, o índice ainda é considerado alto. Os esforços e estratégias das políticas públicas atuais, consubstanciados no Programa de Humanização no Prénatal e Nascimento (PHPN) e na Política Nacional de Atenção Integral à Saúde da Mulher (PNAISM), visando à mudança de paradigma na assistência ao parto, especialmente a redução das taxas de cesariana, ainda não se mostraram eficazes (RATTNER, 2009). Neste cenário de crescente mercantilização da assistência à saúde (SIMÕES-BARBOSA, 2006; CARDOSO, 2008), a preservação de condutas e procedimentos intervencionistas persiste, tanto no setor público como no privado. No entanto, mesmo com a louvável redução no setor público, os índices de cesárea no setor de saúde suplementar estão entre os mais elevados do mundo, alcançando a alarmante taxa de $80 \%$, absurdamente superior aos $15 \%$ recomendados pela Organização Mundial de Saúde (OMS) (BRASIL, 2009a, 2009b, 2010). 
Como consequência, e paradoxalmente, são as mulheres das camadas médias, supostamente com mais informações, maior poder de decisão e com acesso a uma assistência à saúde onerosa e, em tese, de melhor qualidade, as que apresentam atualmente maior vulnerabilidade para a ocorrência desse tipo de parto (MARQUES, 2005; CURY; TEDESCO, 2003; ZORZETTO, 2006; SOUZA, 2002; DIAS et al., 2008). Nesse sentido, a inserção do indicador "Taxa de Cesáreas" no Pacto pela Saúde / Pacto de Gestão foi um passo importante para a organização de sistemas de informação para o acompanhamento das taxas em diferentes níveis de gestão, assim como os parâmetros criados para ambiência na Atenção Humanizada ao Parto e Nascimento em território Nacional, por meio da Resolução de Diretoria Colegiada da Anvisa (BRASIL, 2008; RATTNER, 2009).

Diversos estudos vêm demonstrando a correlação entre maior nível socioeconômico e prevalência de cesariana, indicando forte conexão entre renda familiar elevada, escolaridade alta, acesso à rede privada de saúde e a ocorrência do parto cirúrgico (CURY; MENEZES, 2006; BRASIL, 2009a, 2009b, 2010; MARQUES, 2005; CURY; TEDESCO, 2003). Para entender esse fenômeno, não se pode desconsiderar que as altas taxas de cesariana indicam que os processos de medicalização iatrogênica são, hoje, um fenômeno global relacionado à mercantilização da saúde (SILVER, 1999). Para as situações de risco materno-fetal, o parto cirúrgico constituiu um avanço da medicina tecnocientífica. Porém, o que está sendo aqui problematizado é o quanto a indicação da cesariana pode estar atendendo mais aos interesses mercantis do que à necessidade obstétrica (SOUZA, 2002).

As lacunas existentes na investigação sobre a assistência ao parto neste segmento social foram o ponto de partida deste estudo. O objetivo foi buscar compreender, no plano da subjetividade e das representações simbólicas, como ocorreu o processo de dissonância vivenciado por mulheres de camadas médias, usuárias de planos privados de saúde, que desejavam o parto vaginal no início da gestação mas obtiveram como desfecho uma cesariana.

O parto vaginal (PV), fortemente associado à ideia de imprevisibilidade e sofrimento, vem sendo ressignificado pela biomedicina como um processo fisiologicamente "perigoso". A cesariana, ao contrário, é associada predominantemente à ideia de segurança e de controle sobre os riscos, simbolizada pelo avanço científico e tecnológico (CHACHAN, 2006). Assim, o preço da 
"melhoria" das condições de assistência ao parto foi a desumanização deste processo, o aumento de iatrogenia decorrente do excesso de intervenções médicas desnecessárias e, por fim, a destituição da mulher como protagonista do processo de nascimento. Desta forma, a proliferação do uso de tecnologias médicas com a finalidade de melhorar as condiçôes do parto e preservar a saúde do binômio mãe-filho levou à valorização da intervenção técnica em detrimento da saúde, cristalizando a hegemonia do modelo de assistência biologicista/tecnocrático.

As condições da assistência ao parto no serviço público, em contrapartida, expressam o acesso restrito a recursos técnicos necessários para a população de baixa renda. Esse pano de fundo, contraditório e paradoxal, expõe as desigualdades sociais que persistem na sociedade brasileira e se aprofundam no âmbito das políticas de assistência à saúde, que continuam a penalizar aqueles/as que certamente mais necessitam de atenção e cuidados.

Neste estudo, focalizamos, através da abordagem qualitativa, o processo de interação e negociação, ao longo do acompanhamento pré-natal e parto, de um grupo de mulheres de camadas médias, assistidas no setor privado de saúde, com seus obstetras, e que, a despeito de desejarem o PV, pariram seus filhos através de cesarianas. Para analisar esta questão, consideraremos as estreitas conexões entre as ideologias de gênero e médica, aliadas históricas na instituição do estereótipo da mulher-mãe, em que o poder médico atua na naturalização e na medicalização do corpo feminino, muitas vezes sufocando e/ou manipulando o desejo e os direitos reprodutivos das mulheres, como será apresentado e debatido a seguir.

\section{Referencial teórico-metodológico}

O processo de conhecimento oriundo do campo das Ciências Sociais e Humanas fundamenta este trabalho, que buscou na metodologia qualitativa o alicerce para a interpretação das representações contidas neste paradoxo atual da assistência ao parto: o controvertido caminho entre o desejo pelo PV, expresso por muitas mulheres ao longo da gestação, e a cesariana como desfecho.

A análise qualitativa busca compreender em profundidade os significados e as relações sociais que conformam a subjetividade e a prática de atores/atrizes sociais. Na perspectiva dialética aqui adotada, focaliza-se e se articulam as relaçôes indivíduo e sociedade, estruturas e sujeitos (CHIZZOTTI, 1995). 
O estudo alicerçou-se no materialismo histórico e dialético, uma perspectiva

crítica que revela as contradições da realidade social, a historicidade do fenômeno estudado e suas relaçôes sociais em nível mais amplo. Este referencial teórico é aqui utilizado para abordar e compreender um fenômeno humano - o processo de gestação e nascimento - que se encontra enredado em complexas teias de determinações sócio-históricas que perpassam desde os interesses econômicos e políticos até a subjetividade, incluindo a vivência, a percepção e os significados afetivos e simbólicos deste processo para as mulheres.

O conceito de gênero postula que a posição subalterna das mulheres, na maioria das sociedades, tem causas sociais, econômicas e políticas, confrontando, assim, as explicações que atribuem ao seu papel biológico na reprodução as causas desta inferioridade. Assim posto, o conceito, tomado aqui pela ótica marxista, trava uma discussão crítica sobre o uso abusivo das cesarianas, entendendo-se que este procedimento cirúrgico está fortemente relacionado a interesses mercantis que, visando a aferir lucros, promovem uma mistificação ideológica do nascimento através da naturalização da cesárea (BERMAN, 1997).

Dentro da lógica mercantil que rege a sociedade capitalista, há uma coerência / racionalidade que sustenta o ato cirúrgico, pois este representa menor tempo gasto na sua execução, quando comparado ao acompanhamento do trabalho de parto, que pode levar muitas horas até o nascimento. A cesárea significa, assim, a possibilidade de maior produtividade e mais gastos hospitalares quando comparada ao PV. A estes fatores, soma-se maior produtividade, melhor resultado financeiro e menor desgaste físico e emocional para os médicos, além do fato de que a cirurgia elimina as "surpresas", sob o ponto de vista das "complicaçôes" que podem ocorrer durante a evolução do PV (CURY; TEDESCO, 2003).

Sob a ótica do capitalismo, o conhecimento técnico-científico se transforma em ferramenta que pode ser - e é - utilizada no "comércio" do parto. Estas tecnologias terminam por ancorar os mecanismos de dominação, controle e manutenção do poder político sobre o corpo feminino. Assim, as decisões sobre os procedimentos a serem adotados não costumam levar em consideração a ética e os direitos de cidadania e geralmente ocultam, com argumentos "técnicos", o ganho econômico-mercantil em questão. Esses mecanismos de dominação, que ditam regras e controlam os indivíduos, contribuem para a preservação das normas 
e dos comportamentos dos sujeitos em uma sociedade que incorpora e reproduz o modelo hegemônico de um grupo/minoria privilegiada (BERMAN, 1997).

As mulheres que participaram desta pesquisa, embora pertençam às camadas médias e, como tal, desfrutem de certas vantagens materiais, também vivem suas contradições sociais e de gênero. Os paradoxos entre a esfera reprodutiva e produtiva também estão presentes nessa classe social, onde os conflitos decorrentes de elevada (auto)exigência por um bom desempenho nos papéis materno e profissional estão dialética e conflituosamente entrelaçados e influenciando-se mutuamente.

O instrumento utilizado para a coleta de dados foi a entrevista semiestruturada. Esta técnica visa a apreender as dimensões concreta e simbólica das experiências de vida, os significados, motivos, aspirações, crenças, valores, atitudes e opiniōes, expressos através da fala e de suas expressóes (MINAYO, 1995). Os temas abordados formam as representações de gênero entrelaçadas às experiências da gravidez e do parto, as relações sócio-familiares, o trabalho remunerado, a experiência da maternidade, a avaliação da assistência médica recebida e, por fim, os projetos de vida.

O campo escolhido para o recrutamento das mulheres foi o grupo de apoio à amamentação Amigas do Peito (AP), levando-se em consideração que as mulheres que frequentam as $\mathrm{AP}$, em sua maioria, pertencem aos segmentos médios da população. Foram recrutadas 15 informantes em reuniões realizadas em diversos bairros da cidade do Rio de Janeiro.

Os critérios de elegibilidade para a participação incluíam: mulheres entre 18 e 40 anos, primíparas, com parto ocorrido após 37 semanas, sem intercorrências obstétricas durante a gestação e sem complicações no trabalho de parto, assistidas no setor de saúde privado e pelo obstetra que as acompanhou no pré-natal. Os critérios foram definidos buscando-se minimizar as possibilidades de efetiva indicação médica de uma cesariana. As entrevistas duraram em média duas horas.

A pesquisa foi submetida ao Comitê de Ética em Pesquisa do Instituto de Estudos em Saúde Coletiva e a participação no estudo se deu após as entrevistadas assinarem o Termo de Consentimento Livre e Esclarecido, elaborado conforme capítulo IV da Resolução no 196/96 do Conselho Nacional de Saúde. Todas as informantes autorizaram a gravação das entrevistas. 
A faixa etária das entrevistadas variou entre 25 e 38 anos, sendo a média de 32 anos. A maioria era branca (13), em união estável, com renda familiar média de 14,85 salários mínimos e com empregos no setor privado. Por opção, três entrevistadas não trabalhavam e demonstraram a ambivalência entre "curtir" a maternidade e a frustração por não estarem "produzindo", já que haviam estudado e se preparado para isso. Os bairros de moradia, típicos de classe média, variaram entre as zonas sul e norte, com prevalência da primeira. Todas possuíam $3^{\circ}$ grau completo de escolaridade, sendo que mais da metade (9) possuía pós-graduação.

A maioria iniciou seu pré-natal entre a $4^{\mathrm{a}}$ e $5^{\mathrm{a}}$ semana de gestação, realizando mais de 12 consultas até o parto, o que sugere que as usuárias dos planos privados de saúde começam precocemente o acompanhamento da gravidez. Mais da metade (9) relatou ter entrado em trabalho de parto, sendo que apenas três afirmaram não terem tido nenhuma dilatação do colo uterino. A indução do parto por ocitocina foi utilizada em cinco entrevistadas, revelando a medicalização do parto nos marcos do modelo biomédico. Para seis delas, a cesárea ocorreu antes de entrarem em trabalho de parto, a maioria (5) com menos de 40 semanas de gestação. As dores e limitações físicas pós-cirurgia foram relatadas por 13 entrevistadas, sendo que duas apresentaram também complicações de infecção nos pontos e edema de membros inferiores.

\section{O processo de escolha do parto}

Para as entrevistadas, o processo de escolha do PV foi perpassado por suas vivências individuais e coletivas. Observamos que as entrevistas realizadas a partir do $4^{\circ}$ mês pós-cesárea revelaram uma perspectiva mais crítica sobre a dissonância entre o parto que desejavam e o desfecho em cesárea. Uma possível explicação para isto pode ser a necessidade de certo distanciamento temporal do parto para que as mulheres elaborem e compreendam os processos que viveram. Os depoimentos de duas informantes ilustram esse sentimento:

Então... quando a ficha caiu, me dei conta que ela [obstetra] não tinha nem me examinado e decidiu [pela cesárea], foi um absurdo o que aconteceu, um absurdo eu ter aceitado [...] Ela nem argumentou, apenas anunciou que iria fazer uma cesárea. Pôxa! Eu passei nove meses esperando... como eu pude aceitar!!! Além do absurdo dela não ter me examinado. (Regina, 6 meses pós-cesárea). 
A minha ficha caiu depois... inclusive, quando fui colocar o DIU foi que perguntei para o médico porque a gente não esperou um pouquinho, já que eu estava com quatro de dilatação, de repente eu poderia ter feito parto normal [...] Ele tocou novamente no problema do cordão [circular de cordão]. (Natália, 5 meses pós cesárea).

As motivações para a escolha do PV não variaram muito entre as informantes. A maioria declarou que, por ser este o processo "natural", era a melhor forma para o bebê nascer, além de acreditarem que a recuperação era mais fácil e rápida.

Porque é normal, né? [risos] Porque eu acho que, se a coisa é feita pra ser dessa forma [...] deixa a natureza se encarregar... (Karina)

Escolhi o parto normal porque acho que a recuperação é mais fácil, é melhor pra mulher, pra criança [...] eu queria esperar o tempo dele [do bebê]. (Vitória)

As escolhas não ficaram isentas de momentos questionadores. Algumas verbalizaram que, mesmo decididas pelo PV, internalizavam medos e mitos negativos construídos dentro do contexto sócio-cultural em que vivem.

Confesso que tinha minhas dúvidas... uma amiga me disse que depois do parto, mais tarde, tinha que fazer uma cirurgia do períneo, porque tudo cai... Eu falei: "que nada, não é bem assim". Ainda tem muitos mitos sobre isso... (Dora)

Tanta gente fala coisas horríveis sobre o parto normal, colocam tanto medo, que você acaba, mesmo sem querer, pensando nisso [aspectos negativos associados ao PV]. Ainda bem que isso dá e passa [risos]. A vontade (do PV) é maior. (Rita)

Os depoimentos sinalizaram para a distância entre ter um conhecimento que permite desmistificar "crendices" e o enfrentamento de uma recomendação médica no momento do parto, especialmente quando esta sinaliza "riscos". Algumas falas ajudam a compreender a construção desta difícil escolha, que se contrapóe a uma tendência cultural e social de aceitar a cesariana como o modo "normal" de dar à luz:

[...] até meu chefe falou (a esposa é médica) contra o parto normal: “- Você não vai ter parto normal, nenhum médico quer, enfim, é um transtorno pro médico, cesárea é muito mais moderna, você marca a hora, chega lá e faz, e pronto, entendeu?” (Dora)

Minha chefe [que é médica] foi uma que disse: “- Ah, parto normal só da Bahia pra cima, aqui no Rio de Janeiro já não se faz parto normal. Parto normal é uma coisa anormal, absurda”. Ela falou que parto normal tinha que ser proibido... só cesariana. (Tânia)

A despeito de toda a propaganda em torno das vantagens da cesárea, as falas das entrevistadas corroboram dados de outras pesquisas que também identificaram a 
preferência da maioria das brasileiras pelo PV (DIAS et al., 2008; GIFFIN et al., 2003; ORSI, 2005; TEDESCO et al., 2004; RATTNER et al., 2002). Esses dados confrontam a representação da cesariana como predileção feminina e revelam que, a despeito do marketing, há resistências e questionamentos das mulheres.

\section{A difícil busca pelo obstetra "ideal"}

Para a maioria das entrevistadas, o ponto de partida para a escolha dos obstetras era saber se eram "vaginalistas". Porém, a maioria relatou saber, de antemão, que encontraria dificuldades e limitações nos planos de saúde para encontrarem este perfil de profissional:

Você tem que achar um obstetra que faça parto normal, porque não existe, porque é raro encontrar [...] me alertaram sobre uma "arapuca", mas eu não sabia muito bem que "arapuca" era essa [...] eu era meio inexperiente [...] aí eu falei: tá difícil achar gente que faz parto normal!” (Marta)

Ao indagarmos qual era o sentido de "arapuca", ela respondeu:

Tenho certeza, agora, que essa "arapuca” era porque muitos médicos falam que vão fazer o parto normal, te enrolam e, no fim, por qualquer "coisinha", não querem esperar e fazem cesárea, e você se engana e acredita neles, mas, no final, não tem parto normal nenhum. Descobri mais tarde que tem muita gente [obstetras] assim... (Marta)

O caminho para encontrar o obstetra "ideal", dentro das possibilidades que o plano oferecia, era procurar médicos dos convênios que se declaravam a favor do PV e que se "comprometiam", já na primeira consulta, a realizá-lo.

Outra questão relevante foi a descoberta, pelas entrevistadas, de que muitos obstetras "vaginalistas" não estão conveniados a planos de saúde, o que torna o acesso a eles muito oneroso para a maioria.

Sei que tem médicos que privilegiam essa prática do parto normal, de um parto mais humanizado, que respeitam o tempo, essas coisas... como no parto em casa, por exemplo. Mas, já ouvi falar que é muito caro ter esse tipo de parto, porque ele é muito valorizado. (Carla)

Se a manutenção desses (caros) planos já representa um alto custo econômico no orçamento das famílias de classe média, o custo de um acompanhamento particular torna-se inviável e, sobretudo, injusto. É paradoxal constatarmos que o "retorno à natureza" também é alvo da mercantilização. 


\section{Os círculos interferentes - os companheiros e as relações familiares}

De acordo com as depoentes, a maioria dos companheiros as apoiou na opção pelo PV. Porém, próximo ao parto, algumas pressões começaram a interferir no comportamento da maioria deles e foram suficientemente significativas para que muitos, nesse momento, mudassem de posição:

[...] quando a médica disse que ia ter que ser cesárea, na verdade ela não explicou muito, apenas disse que não era bom esperar mais [38 semanas e meia], e marcou para o dia seguinte. Ele [companheiro] ficou muito ansioso, disse que não queria que nós duas corrêssemos nenhum risco. Ele disse pra mim que não podíamos, nesse momento, criar nenhum clima de desconfiança com a médica, que era melhor aceitar, pois seria melhor pra nossa filha [...] Eu acho que a gente, na hora que recebe a notícia da cesárea, fica tão confuso que não questionamos, você já ta num momento, num "clichê", tipo assim, então vamos resolver..." (Dora).

Outras entrevistadas, cujos companheiros não compartilhavam a escolha pelo $\mathrm{PV}$, relataram que estes, convencidos que a cesárea seria a opção mais segura, tentaram persuadi-las:

Meu marido sempre quis que eu fizesse cesárea. A ex-esposa dele teve três cesáreas. Sempre disse que a cesárea é mais garantida porque pode marcar hora e evita acontecer alguma coisa. Mesmo assim, eu disse que queria o parto normal e que ia tentar. (Elis)

Ele [companheiro] tinha essa vontade de eu não fazer normal [...] No final da gravidez o bebê ficou muito grande, e aí meu marido ficou na minha "cabeça": "- Viu, é melhor cesárea... Aí eu me senti muito pressionada nesse momento (Joana, cesárea com 39 semanas).

A cristalização sociocultural da ideologia da cesariana pode estar afetando também os homens, que parecem ter assimilado os mesmos medos que as mulheres - medo da dor, do sofrimento, da imprevisibilidade - desempenhando, assim, uma influência desfavorável sobre suas companheiras.

No círculo de relações parentais e sociais das entrevistadas, um número significativo de mulheres próximas tinha se submetido a cesarianas, independentemente de ter sido por escolha ou indicação obstétrica, aumentando a pressão para este tipo de parto:

Quase todas as mulheres que eu conheço tiveram cesariana, mas sei que muitas também queriam ter parto normal, mas não conseguiram. Algumas falaram que escolheram a cesárea desde a gravidez, mas são poucas. Sabe... hoje não tá fácil fazer parto normal, nem pra quem quer (Rita). 
Todo mundo achou bacana a minha escolha pelo parto normal... a minha sogra, todo

mundo da família, todo mundo falava: "ai, que bom que você vai tentar, mas... a fulana não conseguiu por isso, fulana não conseguiu por aquilo...” todo mundo tem uma história pra dizer que não conseguiu (Dora).

\section{A dissonância entre o desejo e a realidade}

Para a maioria das entrevistadas, até o final da gestação, existia uma forte expectativa pelo momento do parto. Durante as consultas, algumas delas se preocupavam em obter, dos obstetras, a garantia de que iriam esperar o trabalho de parto se deflagrar.

Ela falou [obstetra]: “- Olha, já está com 39 semanas, você quer esperar mais? Ele [bebê] está grande e pesado, e aí vai ser complicado para o parto normal”. Aí eu fiquei preocupada com isso. Me senti muito pressionada (Joana).

Ela [obstetra] ficava me pressionando: “- Veja lá o que você vai fazer. Você está entrando em trabalho de parto e não vai ter lugar [maternidade] para ter o seu filho. Vamos marcar logo essa cesariana!" Não tinha saída, como ia mudar de médico naquele momento, começando a sentir contração?! Ela acabou me convencendo e eu fiquei com medo de não ter vaga mesmo. Não tinha mais dúvidas: ia fazer uma cesárea desnecessária... Fui pra casa arrasada (Regina).

Os relatos revelaram várias manifestações - explícitas ou sutis - das pressōes sofridas pelas mulheres para aceitarem a cesariana. Corroborando esses achados, diversos estudos já apontaram para "justificativas duvidosas"para a realização da cirurgia (DIAS et al., 2008), parecendo existir uma "predisposição médica" para a indicação, muitas vezes antes do término da gestação. Esses mecanismos, que envolvem as relações de confiança entre mulheres e obstetras, construídas ao longo do pré-natal, favorecem a aceitação do parto cirúrgico. O pano de fundo desse cenário é o medo infundido na mulher da ocorrência de um fato negativo, caso insista em tentar o PV. A "responsabilidade" da decisão é repassada, muitas vezes, para ela.

Supomos que nenhuma mulher, conscientemente, colocará em risco a vida de seu filho apenas para concretizar a realização de um desejo de parir por PV. Assim, é possível e provável que alguns médicos possam utilizar argumentos para trabalharem a "medicalização dos medos maternos" (DIAS et al., 2008). Desta forma, são cesáreas justificadas com o "consentimento" das mulheres. A fala a seguir desvela a angústia e a dificuldade perante o inevitável: 
[...] cheguei na maternidade $\mathrm{X}$ e fui examinada pela médica de plantão, que disse que eu estava entrando em trabalho de parto e que estava tudo bem. Perguntou se eu queria normal ou cesárea, e quando falei que queria normal, ela disse que eu poderia até ir pra casa e depois voltar, que eu tinha tudo pra fazer parto normal [...] Aí a minha médica chegou dizendo:"- Olha a gente vai fazer uma cesariana”. Eu falei pro meu marido:"- Ela nem me examinou, como pode fazer isso, dizer que tem que ser cesárea?!" Caí numa armadilha! Ela tinha acabado de sair de um plantão, sem dúvida, estava visivelmente exausta. Já tinha marcado a cesárea, então, ela pensou: ”- Vamos cortar e pronto!" (Regina).

\section{Os sentimentos da experiência da cesariana}

Para a maioria das informantes (nove), não ter vivido a experiência do PV representou uma grande frustração, pela qual se culpam.

Ah! Eu me senti, na hora, a pior das mulheres. Minha decepção toda era que eu queria parto normal. Quando eu penso, fico triste... eu pensava, na hora... eu me senti uma pessoa inútil (Célia).

Me sinto envergonhada em primeiro lugar, frustrada e com certeza de não querer repetir isso [outra cesárea desnecessária]. E que posso, sempre fiz, o que eu quis da minha vida e nesse momento, que considero o mais importante da minha vida, eu não consegui dominar. Então, foi minha culpa de não ter batido o pé naquela hora... Fiquei o tempo todo igual a uma idiota. Não consegui ter forças pra negociar... foi imposta a decisão dela [da médica], uma situação desigual. Eu não vi minha filha saindo de dentro de mim... (Regina).

Não me perdôo por isso, estava pressentindo que ela [obstetra] não iria fazer parto normal, mas acabei me acomodando, com medo de trocar de médico e não adiantar nada, trocar seis por meia dúzia. $\mathrm{Na}$ verdade, as mulheres pensam que escolhem o que querem [o tipo de parto], mas não é bem assim. Eles [médicos] prometem mas não cumprem. Você fica crente que vai ter seu "partinho" normal e eles vêm com uma desculpa qualquer, qualquer motivo e "metem" uma cesárea e, às vezes, você ainda dá graças a Deus porque ele decidiu pela cesárea pra não ter problemas pro bebê (Joana).

A sensação de impotência para enfrentar as relações desiguais com seus obstetras, especialmente em um momento tão delicado, e as incertezas de não terem sido corajosas o suficiente, de não terem "batido o pé", como disse uma delas, contra a decisão comunicada, afetam sua auto-estima e confiança em si próprias, o que pode deixar marcas duradouras. No entanto, nem todas as mulheres reagem da mesma forma a esta situação. Outra parte do grupo (seis) relatou ter elaborado satisfatoriamente a não realização do PV. 
Olha, não fiquei decepcionada, frustrada por ter sido cesariana. O que pesou mais era que eu queria que meu filho nascesse bem. Tinha consciência de que, se não desse, se tivesse riscos para a saúde dele [bebê], teria que fazer uma cesárea [...] Minha médica tinha colocado que, pela minha estrutura [bacia "estreita"] e o tamanho da criança, talvez não fosse possível o parto normal, mas eu "deletava” a informação e dizia: “- Eu posso ter meu filho de parto normal, sim”. O fato de ter feito a cesariana já não tem tanta importância, já superei isso (Fernanda, 3 meses pós-cesárea).

Eu tentei, não deu, pelo menos eu queria que fosse no tempo dele [referindo-se a ter entrado em trabalho de parto] e foi. Isso [ter feito cesárea] não me incomodou, eu absorvi bem, até acho que a recuperação foi boa, melhor do que eu pensava, então não fiquei com "traauuma” [entonação feita por ela] (Vitória, 3 meses pós-cesárea).

A “certeza" de estarem evitando riscos para o bebê parece atuar como mecanismo de defesa para uma melhor aceitação da cesariana. A introjeção do resultado "positivo" da cirurgia foi sinalizada pela OMS como um fator preocupante pois transforma a cesariana em referência de "segurança".

Surpreendentemente, apesar da consciência crítica demonstrada por muitas entrevistadas, a maioria revelou que manteria os mesmos obstetras em uma nova gestação. A incerteza da mudança parece estar relacionada à convicção de que outros profissionais agem da mesma forma e, como já construíram com o atual obstetra uma relação de "confiabilidade", não valeria a pena "correr riscos". Manifesta-se assim um "conformismo", como se essas mulheres percebessem que, individualmente, são impotentes para mudar essa situação. Também fica evidenciada uma concepção de cuidado em saúde que dissocia a competência técnica da postura ética, o que contraria frontalmente os princípios preconizados pelo PAISM e pelo PNHP. A fala abaixo é emblemática desta questão:

Correr o risco de uma nova cesárea, com certeza vou correr. Tenho plena consciência de que para o obstetra é mais cômodo [fazer cesárea], mas para colocar uma criança no mundo você tem que ter um profissional que seja de sua confiança, não adianta escolher outro porque esse [obstetra atual] não gosta de parto normal. E, de repente, o outro que eu escolher não atende a todas minhas expectativas, as minhas necessidades, não me diga os riscos que existem [durante o PV]... Acho que correria riscos com a mudança de médico. Tem que ser um médico que você tenha plena confiança (Natália).

Ao analisarmos os depoimentos, percebemos o quanto a maternidade ainda é uma vivência conflitiva para as mulheres. Para a maioria, ainda parece ser muito difícil compor os múltiplos papéis - mulher/esposa/profissional/mãe. Como mulheres atuantes no mercado de trabalho, com boa formação acadêmica, sabiam que enfrentariam dificuldades para conciliar a maternidade com as exigências do 
sistema capitalista, altamente competitivo e que espera das mulheres um bom desempenho profissional, materno e doméstico:

Consegui ficar os quatro meses de licença [maternidade], mas estava sentindo saudades do trabalho. Ficar o tempo todo com o bebê, por mais que seja prazeroso, e eu tenha curtido muito, chega uma hora que a gente fica pensando em voltar. Só que, quando chega a hora... dá um vazio, você chega no trabalho e fica dando uma vontade louca de sair correndo e abraçar seu filho. Não está sendo fácil me adaptar, ter que ficar tanto tempo longe dele. Seria bom poder conciliar trabalhando só meio expediente, mas isso é impossível (Luisa).

Assim, o estudo evidenciou o quanto a gestação, o parto e a própria experiência da maternidade estão circunscritos em uma sociedade que ainda não confere à maioria das mulheres o direito de fazer escolhas, o que reafirma a importância da luta pelos Direitos Reprodutivos, especialmente no campo da assistência à saúde.

\section{Considerações finais}

Tendo por objetivo compreender os mecanismos objetivos e subjetivos que legitimam a "cultura da cesárea", esta pesquisa problematizou as percepções, experiências e a análise crítica de mulheres de camadas médias sobre a escolha do parto, em um cenário de abuso da cesariana. A visão crítica adotada pretendeu ir além das aparências, buscando captar a complexidade das questões que estão entrelaçadas a este fenômeno - materiais e simbólicas, objetivas e subjetivas, individuais e coletivas -, revelando o quanto a saúde é um campo perpassado pelas relações sociais.

A pesquisa mostrou como a transição de gênero também afeta as mulheres das camadas médias - um segmento usualmente tomado como "privilegiado" e que, por isso, tem seus problemas e contradiçóes minimizados. As crescentes demandas do mundo produtivo, em um contexto cada vez mais competitivo e seletivo, tornam a decisão de ter (e criar) filhos uma experiência conflitiva também para as mulheres deste segmento.

Sendo esta uma pesquisa exploratória, é importante ressaltar que, a partir de novas leituras, outras considerações poderão emergir, visto que o mesmo objeto, quando observado em outro momento e por outros ângulos, estará sujeito a novas interpretações. A perspectiva dialética adotada postula que cada fenômeno, abordado em sua singularidade, não pode ser desconectado de sua totalidade, possibilitando (re)leituras de acordo com o seu “tempo" histórico. 
Como os dados evidenciaram, a possibilidade de escolha do tipo de parto pelas mulheres de camadas médias - com profissóes universitárias prestigiadas, bom nível socioeconômico e que pagam (caros) planos de saúde para garantirem uma assistência de qualidade - não está dada. Como revelado pelas entrevistadas, seu suposto "poder de decisão", no momento do parto, fica altamente fragilizado pelos sutis ou explícitos mecanismos através dos quais opera, de forma articulada, o poder médico e o "mercado" da saúde.

Postulamos, portanto, que a escolha pelo tipo de parto deve ser um direito inalienável das mulheres e dos casais e não uma condição imposta por tantos segmentos que não estão, necessariamente, interessados na promoção da saúde e nos direitos sexuais, reprodutivos e de cidadania. ${ }^{1}$

\section{Referências}

BERMAN, R. Do Dualismo de Aristóteles à Dialética materialista: a transformação feminista da ciência e da sociedade. In: JAGGAR, A.; BORDO, S. (orgs). Gênero Corpo Conhecimento. Rio de Janeiro: Rosa dos Tempos, 1997. p. 241-275.

BRASIL. Ministério da Saúde. Agência Nacional de Saúde Suplementar. Disponível em: www.ans.gov.br Acesso em: 25 fev 2010.

Datasus. Sistema de Informaçôes Hospitalares. SIH/SUS. Disponível em: http:// www2.datasus.gov.br/DATASUS/index.php?area=02 Acesso em: 28 out 2009.

Pesquisa Nacional de Demografia e Saúde da Criança e da Mulher. Disponível em: www.agenciabrasil.gov.br Acesso: 18 out 2009.

- Agência Nacional de Vigilância Sanitária. Resolução da Diretoria Colegiada RDC n. 36/2008. Regulamento Técnico para Funcionamento dos Serviços de Atenção Obstétrica e Neonatal. Brasília: MS, 2008.

CARDOSO, J.E. A dissonância entre desejo e realidade: A escolha da via do parto pelas mulheres de camadas médias no Rio de Janeiro. Dissertação (Mestrado em Saúde Coletiva) - Universidade Federal do Rio de Janeiro, Instituto de Estudos em Saúde Coletiva, Rio de Janeiro, 2008.

CHACHAN, A.S. Médicos, mulheres e cesáreas: a construção do parto normal como "risco" e a medicalização do parto no Brasil. In: Simpósio Internacional Fazendo Gênero. Universidade Federal de Santa Catarina, Florianópolis, 2006.

CHIZZOTTI, A. Pesquisa em Ciências Humanas e Sociais. 2 ed. São Paulo: Cortez, 1995. CURY A.F.; MENEZES P.R. Fatores associados à preferência por cesariana. Rev. Saúde Pública, São Paulo, v. 40, n.2, p.227, 2006. 
CURY A.F.; TEDESCO J.J.A. Aspectos polêmicos na indicação de cesariana. Femina, v.31, n.9, p.809-12, 2003.

DIAS M.A.B. Cesariana: epidemia desnecessária? A construção da indicação da cesariana em uma maternidade pública do município do Rio de Janeiro. Dissertação (Mestrado em Saúde da Mulher e da Criança) - Instituto Fernandes Figueira, Fundação Oswaldo Cruz, Rio de Janeiro, 2001.

DIAS M.A.B. et al. Trajetória das mulheres na definição pelo parto cesáreo: estudo de caso em duas unidades do Sistema de Saúde Suplementar do Estado do Rio de Janeiro. Ciência e Saúde Coletiva, v.13, n.5, p.1521-1534, set-out 2008.

GIFFIN, K et al. Parto cesáreo: quem o deseja? Em quais circunstâncias? Cad. de Saúde Pública, Rio de Janeiro, v.19, n.6, p.1611-1620, 2003.

MELO, V.H. Evolução histórica da obstetrícia: a marginalidade social das parteiras e da mulher. Dissertação (Mestrado em Saúde da Mulher) - Faculdade de Medicina, Universidade Federal de Minas Gerais, Belo Horizonte, 1983.

MINAYO, M.C.S. O conceito de Representaçôes Sociais dentro da sociologia clássica. In: GUARESCHI, P. ; JOVCHELOVITCH, S.(orgs). Textos em Representaçôes Sociais. Petrópolis: Vozes, 1995. p. 89-111.

MARQUES R.R. Desigualdades sociais no parto: fatores associados ao atendimento público e privado em Joaçaba, SC. Dissertação (Mestrado em Saúde Coletiva) - Faculdade de Medicina, Universidade do Oeste de Santa Catarina, Joaçaba, 2005.

ORSI, E. et al. Qualidade da atenção ao parto em maternidades do Rio de Janeiro. Rev. Saúde Pública, São Paulo, v.39, n.4, p. 646-654, 2005.

RATTNER, D. et al. O parto como eu vejo ou como eu o desejo? Expectativas de gestantes, usuárias do SUS, acerca do parto e da assistência obstétrica. Caderno de Saúde Pública, Rio de Janeiro, v.18, n.5, p.1303-1311, 2002.

RATTNER, D. Humanização na atenção a nascimentos e partos: ponderações sobre políticas públicas. Comunicação, Saúde, Educação; v.13, supl.1, p.759-68, 2009.

RATTNER, D. Humanização na atenção a nascimentos e partos: breve referencial teórico. Comunicação, Saúde, Educação, v.13, supl.1, p.595-602, 2009.

SILVER, L.D. Direito à saúde ou medicalização da mulher? Implicações para avaliação dos serviços de saúde para as mulheres. In: GIFFIN, K.; COSTA, S.H. (org.). Questōes de Saúde Reprodutiva. Rio de Janeiro: Fiocruz; 1999. p. 299-317.

SIMÔES-BARBOSA, R.H, Humanização da assistência à saúde das mulheres: uma abordagem de gênero. In: DESLANDES, S.F. (org). Humanização dos cuidados em saúde: conceitos, dilemas e práticas. Rio de Janeiro: Fiocruz, 2006. p. 323-350. 
SOUZA M.R. Parto: entre o desejo e a realização. In: Encontro da Associação Brasileira de Estudos Populacionais (ABEP), ANAIS, realizado em Ouro Preto, Minas Gerais, Brasil de 4 a 8 de novembro de 2002 .

TEDESCO R.P. et al. Fatores determinantes para as expectativas de primigestas acerca da via de parto. Revista Brasileira de Ginecologia e Obstetrícia, v.26, n.10, p.791-798, 2004.

VIEIRA, E.M. A medicalização do corpo feminino. Rio de Janeiro: Fiocruz, 2002.

ZORZETTO, R. Escolha errada. Revista Pesquisa FAPESP, n.124, p.39-44, 2006.

\section{Nota}

${ }^{1}$ J.E. Cardoso realizou a coleta, análise, interpretação dos dados e redação do artigo. R.H.SimôesBarbosa colaborou na interpretação dos dados e participou da redação e revisão do artigo. 


\section{Abstract}

\section{Disagreement between desire and reality: cesarean "industry" among middle class women in Rio de Janeiro, Brazil}

This paper presents results of a qualitative research that aimed to apprehend and understand, among middle class women's perception and experience, the disagreement / distance / gap between primary vaginal labor option and a cesarean outcome. Fifteen women who had a private health insurance plan were interviewed about their experiences and perceptions related to their prenatal care and parturition process. Results showed a pervasive or explicit intervention of the obstetrician on women's choice, influencing on the cesarean outcome and suggesting that, for many women, it is still difficult to escape from the "trap" of the mercantilist, intervening and "iatrogenic" biomedical model, which is still firmly institutionalized and legitimated in our society. These results intend to collaborate with actions aimed to promote women's citizenship related to the right to make decisions on their reproductive choices, preserving and undertaking the parturition experience as unique and indefeasible right for all women, their partners and relatives.

> Key words: cesarean section; middle class; gender; reproductive rights. 